\title{
Howard Zonana and the Transformation of Forensic Psychiatry
}

\author{
Richard J. Bonnie, LLB
}

In recognition of Howard Zonana's contributions, I take stock of the progress of the field of forensic psychiatry over three decades. As forensic psychiatrists, you are the voice of psychiatry in the law and the interpreter of law to your colleagues in psychiatry. I offer provisional impressions of your collective accomplishments under three themes: expertise, influence, and integrity. First, you have established and nurtured the expertise and authority of forensic psychiatry, which has become increasingly evidence-based and reflects a prudent sense of humility. Second, you have had a significant influence on the design and daily application of mental health law in both criminal and civil spheres. Through the American Academy of Psychiatry and the Law (AAPL) and relevant components of the American Psychological Association, you have been a strong and effective advocate for protecting both the needs and rights of people with mental illness and have had demonstrable influence in the Supreme Court as well as at the grassroots. Finally, you have nurtured and protected the ethical integrity of the profession in the face of ever-increasing challenges, due in no small measure to the habits of ethical reflection that Howard Zonana has modeled and taught over the course of his extraordinary career.

J Am Acad Psychiatry Law 38:570-6, 2010

We are here today not only to celebrate Howard but also to acknowledge and applaud the advances of the field to which he has devoted his career and for which he deserves a fair share of the credit. Undoubtedly, Howard's colleagues in forensic psychiatry are nodding in agreement with these observations. But my praise for Howard, and for the field, is perhaps more noteworthy than yours because it comes not from a fellow psychiatrist but from an observer outside the field and, even more so, from a lawyer.

And from an aging lawyer at that. Among the few virtues of aging is the potential for personal reflection on the past, an opportunity by definition not open to young people. (You will note that I have set the bar very high for myself.)

Before I get to that, though, I want to make a few personal observations about Howard, with whom I have worked and from whom I've learned for about 30 years. I can safely say in this gathering that Howard has a distinct persona. You know a lot about me just by looking at my dark suit and my bland,

Mr. Bonnie is Professor of Medicine and Law, Professor of Public Policy, Professor of Psychiatry and Neurobehavioral Sciences, and Director, Institute of Law, Psychiatry and Public Policy, University of Virginia, Charlottesville, VA. Address correspondence to: Richard J. Bonnie, LLB, University of Virginia School of Law, 580 Massie Road, Charlottesville, VA 22903. E-mail: rbonnie@virginia.edu.

Disclosures of financial or other potential conflicts of interest: None. blue tie. What would you know about Howard by looking at his loosened tie, his ever-present backpack, and the curling hair on the back of his balding pate? An inveterate hiker for sure. A Yale English professor, perhaps. But a psychiatrist?! A forensic psychiatrist?!

Dr. Chips, perhaps. That image would begin to bring Howard's gentle, thoughtful, understated demeanor into focus. Perhaps it is even more evocative to say he is the Dalai Lama of forensic psychiatry. As that one sinks in, I think you know I'm onto something. Is it too much to say that Howard Zonana has been the keeper of the soul of forensic psychiatry? Is it an exaggeration to say that Howard has been for forensic psychiatry what his mentor Jay Katz was for bioethics?

Musing about Howard's contribution in this way leads me nicely to the point of departure for my substantive remarks.

\section{Age of Reform}

Modern forensic psychiatry has its roots in the same intellectual ferment of the late sixties and early seventies that produced the field of bioethics. Henry Beecher's article on the ethical deficiencies of recent biomedical research was published in the New England Journal in 1966. ${ }^{1}$ The Tuskegee experiment 
became public in $1972 .^{2}$ The Belmont Conference was convened in 1978, and the Commission's Report was published in $1979 .^{3}$

The Nuremburg trials ${ }^{4,5}$ and subsequent disclosures regarding abuses of subjects of human research in this country highlighted the central importance of respecting individual autonomy and protecting vulnerable people from exploitation and neglect. These concerns, and the accompanying distrust of medical authority, eventually and inevitably focused attention on prevailing practices relating to involuntary commitment to state psychiatric facilities, where more than a half million people resided. These concerns provided a human rights underpinning for the widely supported vision of transforming the mental health system from one based on institutional care to one based on community care. These efforts also received a constitutional underpinning when Justice Douglas practically invited litigation challenging procedures and criteria for civil commitment in the Court's first decision relating to civil commitment in 1966. ${ }^{6}$ Over the ensuing 15 years, the Supreme Court's due process revolution exposed almost every corner of mental health law to judicial scrutiny. ${ }^{7-14}$ The ferment was not limited to the civil arena, of course. Deinstitutionalization and concerns about overextensions of the criminal law also invited a wholesale rethinking of the relationship between mental health and criminal justice, from arrest through sentencing. ${ }^{15}$

A cross-cutting theme of all these reforms was a challenge to psychiatric expertise and authority, especially in the courtroom, where a psychiatrist's opinion was typically the sole predicate for orders issued under commitment and guardianship statutes. This growing challenge to psychiatric authority was rooted primarily in doubts about the scientific basis for psychiatrists' opinions about mental illness, dangerousness, or competence. ${ }^{16}$ However, critics of mental health law also criticized the laws and practices that turn these decisions over to psychiatrists in the first place, arguing that attributions of responsibility, incompetence, and dangerousness inevitably require value judgments rather than simple findings of clinical fact. ${ }^{17}$

Paul Appelbaum has described this turbulent period in his award-winning book, Almost a Revolution, ${ }^{18}$ and I will not try to cover the territory here. Paul focused on the content of the reforms of mental health law adopted during this period, showing that the changes were not as profound as the rhetoric accompanying them might have portended. For my purposes, the outcomes are of less interest than the unsettling nature of the changes that were being sought and the intensity of the debates they evoked. Even if the intellectual turbulence of this period did not, in the end, revolutionize the law, it did transform the field of forensic psychiatry by propelling the field forward with a new agenda, marked by new challenges.

This period was a cauldron of reform, and the opportunity to taste the excitement and, perchance, to make a contribution attracted a new generation of legally minded psychiatrists, including Howard, to a new and exciting field. A generation of young lawyers was also drawn into the fray by the opportunity to forge laws and public policies out of powerful new ideas. They were also joined by psychologists whose similar inclinations drew them into an emerging specialty of community psychology and a new crosscutting subspecialty of psychology and law. ${ }^{19}$

Among psychiatrists, the field of law and psychiatry was not created from scratch, of course. It was built on a long and distinguished tradition of expert consultation for the courts and public leadership by a group of very distinguished psychiatrists, including Manfred Guttmacher, Karl Menninger, Seymour Halleck, Seymour Pollack, and Jonas Rappeport, to name a few. But the forces I have described had a transformative effect on the agenda and ambition of the field.

One point worth noting about these intellectual and institutional forces is that most of them originated outside psychiatry itself. To some extent, the swirl of these external forces, especially litigation challenging customary practices in psychiatric care, tightening the criteria for involuntary treatment, and challenging the expertise of psychiatry, led many psychiatrists to view the profession as being under siege and desperately needing an organized defense. Although psychiatrists themselves were not of one mind about the merits of the reforms and many of them shared the reformers' concerns, it was clear to everyone that the voice of organized psychiatry needed to be heard, and it soon was.

The American Academy of Psychiatry and the Law (AAPL) was established in 1969 and its leaders set out to reshape the field of forensic psychiatry, to strengthen the scientific foundation and legal sophistication of forensic practice, and to build the institu- 
tional architecture for formal subspecialization. The American Psychiatric Association (APA) created the Commission on Judicial Action (CJA) in 1974 to present the views of organized psychiatry to the courts, and established the Council on Psychiatry and Law (CPL) in 1979 to prepare model statutes and regulations for legislatures and executive agencies. (Actually, when it was established in 1979, what is now called the Council on Psychiatry and Law was named the Council on Psychiatry and Governmental Policy.) This latter effort was initiated by Alan Stone when he assumed the presidency of the APA and he subsequently chaired the Council after his term. The overlapping leadership of AAPL, the CJA, and the CPL represent the leadership of the field.

\section{Current Status}

It has now been four decades since AAPL was founded and three decades since the Council on Psychiatry and Law was established. Perhaps it is fitting, on the occasion of this celebration of Howard's career, to take stock of how well he and you, collectively speaking, have done. You have served as the voice of psychiatry in the law, and as the interpreter of law to your colleagues in psychiatry. What has been accomplished? Some young historian (or historically minded psychiatrist) should take on the assignment of describing and evaluating your work and its impact on your profession, on public policy, and on the path of the law. I am certainly not going to attempt that ambitious task here. However, in my remaining time, I will offer a few provisional impressions for your consideration. I warn you in advance that I will offer no evidence in support of them aside from my own ruminations. I will collect them under three themes: expertise, influence, and integrity.

\section{Expertise}

My first observation is that you (collectively) have established and nurtured the expertise and authority of forensic psychiatry. We are all aware of occasional cases in which highly speculative or value-driven testimony is offered as if it were based on science and systematic clinical experience. It is testimony of this kind that gives psychiatry a bad name, and accounts for all-too-frequent judicial observations about the unreliability of psychiatric testimony. Indeed, I sometimes wince upon reading transcripts of testimony rife with unwarranted assertions of certainty where qualification, restraint, or nuance was needed.
I will venture the provisional claim that such testimony occurs with markedly less frequency now than it did before AAPL was established and before subspecialization became fully implemented. Systematic data to support this claim would be virtually impossible to assemble, but I believe it to be true. I assume that you share this belief as well. If we are right, what are the operative factors? I will offer a couple of very general hypotheses. First, I believe that forensic evaluations are more thorough and more evidence-based than they were 40 years ago. Second, I believe a prudent sense of humility has become a cardinal feature of modern forensic psychiatry. What I mean by this is that well-trained forensic experts are acutely aware of what they know and what they don't know and are careful to frame their opinions accordingly. Prudent self-restraint does not eliminate disagreement, of course, but it does help to clarify the basis for the disagreements, and it generally avoids the sorts of disagreements that arise when one (or both) of the contending experts overlooks pertinent data or fails to understand the limits of his or her own knowledge.

The courts can do only so much to assure that expert testimony by properly credentialed witnesses is of high quality. Daubert does not really help with opinions based on the usual tools of clinical assessment in psychiatry. ${ }^{20}$ (Daubert held that the test for admitting scientific evidence under the Federal Rules of Evidence is a "flexible" one, encompassing a variety of factors aside from whether the expert's theory is generally accepted within the field, including the "falsifiability" of the underlying theory, the extent to which it has been subject to peer review, and its known or potential error rates. Rule 702 of the Federal Rules of Evidence has codified the Daubert approach.) It appears that the clinical opinion testimony offered by psychiatrists and other mental health professionals in the courtroom is rarely challenged on Daubert grounds.

Quality can be assured only if standards of practice are developed, disseminated, and, when necessary, enforced by the profession itself. I stand in praise of AAPL because it has pointed the way toward thoughtful self-evaluation by its members through its educational activities and has used its superb clinical guidelines to establish practice standards. ${ }^{21-23}$ AAPL's approach should be emulated by other scientific and clinical disciplines when they venture into the courtroom. 


\section{Digression on the "Ultimate Issue" Problem}

I'm going to take a brief digression from the main line of my talk to make a few comments about the so-called "ultimate issue" problem. As you know, one of the most common sources of disagreement in expert testimony is differing opinions on the ultimate issue. The witnesses may agree about most, if not all, of their clinical observations, diagnoses, and the nature of any legally relevant functional impairments, but they nevertheless reach different conclusions on the ultimate question before the court (e.g., whether the defendant is competent to stand trial or was insane at the time of the offense). Such disagreements are to be expected in some cases because the experts disagree about the degree to which the defendant's capacity was impaired, which then might slide into a difference of opinion on the application of the legal standard. Some purists would say that the experts should simply describe the degree of impairment and express no opinion on the application of the legal criterion because that conclusion inevitably rests on a value judgment. ${ }^{16,24}$

If that is what the argument is about, I am not a purist. I have no objection to ultimate issue testimony under these circumstances because the factual analysis of the degree of impairment and its sufficiency for legal purposes are conflated in a single phrase. All the judge needs to do is give the usual instruction that it is up to the jury to apply the standard. That is fine as long as the experts and the jury are applying the same standard. (The ABA standards bar testimony that the defendant was or was not insane, but permit testimony that he was or was not able to appreciate the wrongfulness of his conduct at the time of the offense. $)^{25}$

However, the problem is sometimes quite a different one, because the experts have a different understanding of what the standard actually is and are defining it differently. When this is the problem, it is up to the lawyers to elicit the basis for the disagreement and to ask the judge to define the terms so that the experts are using it in the same way when they express their conclusions. However, the process often doesn't operate as it should, because the lawyers and the judges aren't doing their job. They elicit the testimony without clarifying its hidden suppositions, and, as a result, the experts are actually using the words of the standard to mean different things. In effect, they are not responding to the same ques- tion. ${ }^{26}$ My favorite illustration of this problem comes from the Hinckley case. ${ }^{27}$

The question was what "appreciation of wrongfulness" meant in the D.C. Circuit. During the pretrial arguments on this issue, the prosecution (Roger Adelman) argued that the language should be given what he called a purely "cognitive" meaning, while the defense (Vincent Fuller) argued that the term encompasses "not only a verbal cognizance or simple awareness of the wrongfulness of his actions, but an affective or emotional understanding of his conduct as well" (Ref. 27, p 50). Judge Parker ruled that he would "approach the word appreciation ... within the context of a cognitive definition" (Ref. 27, p 50) - an incorrect reading of the law, in my opinion. However, when it came time for the defense expert (Dr. William Carpenter) to testify, the judge allowed him to frame his testimony by using a broader "affective" definition of appreciation, thereby allowing him to concede that Hinckley has a "purely intellectual understanding that what he did was illegal" while concluding that he lacked an emotional appreciation of the consequences of his acts because he interpreted those acts solely in terms of his delusional "inner world." Then, when the chief prosecution witness (Park Dietz) testified, he framed his testimony in terms of the narrow cognitive definition and opined that emotional factors were irrelevant. When Judge Parker instructed the jury, he did so in the bare language of the insanity test ("appreciation of wrongfulness") without defining the term at all.

The point of this digression is that when these problems of translation arise, the failing more often lies with the courts than with the experts. I suspect that this problem is better recognized among forensic psychiatrists than among lawyers and judges because the experts know exactly what they are disagreeing about and the lawyers (typically not repeat players in insanity adjudications) do not. In this respect, welltrained forensic psychiatrists can help to educate lawyers and judges about their own responsibilities.

\section{Influence}

My second broad complimentary observation is that you collectively have had a significant influence on the design and daily application of mental health law in both criminal and civil spheres. Most important, the APA has been a strong and effective advocate for protecting both the needs and rights of people with mental illness. As Paul Appelbaum has 
documented so well (Ref. 18, Chapters 2-4), the APA's decision to stake out a fully developed and coherent legal position emphasizing the therapeutic purposes of and justifications for civil commitment and involuntary treatment ${ }^{28}$ had a major corrective influence in the legislatures and in the courts by providing a persuasive alternative to the libertarian model that had emerged in the 1970s. Through its briefs in the Supreme Court, its model commitment law, and numerous task force reports and resource documents on a wide range of issues, including seclusion and restraint, mandatory outpatient treatment, and the duty to protect, the CJA and the CPL have faithfully and effectively carried out the mission for which they were created. The influence has been evident at the top (in the Supreme Court) as well as at the grassroots.

Less well-documented has been your collective influence on competence determinations in criminal justice. I am referring not only to the everyday practice of pretrial evaluations (about 60,000 such evaluations every year), ${ }^{29}$ but also to the design of the applicable criteria by appellate courts. Psychiatrists are trained to focus attention on the unique frailties and needs of each individual, and your training and expertise are extremely valuable because you can help judges and lawmakers understand the clinical realities of mental disorder as well as the practical utility of treatment. This is a critically important role in the dispensing of humane justice, and forensic psychiatrists do it every day in every courtroom in the land by assisting in adjudications of competence and responsibility.

The law does not prize individualized justice above all else. Indeed, as well-informed forensic psychiatrists, I'm sure you appreciate that legal rules and standards must be framed with sufficient specificity and objectivity to permit reasonably consistent application. Several recent Supreme Court cases provide good illustrations of the tension between individualization and efficient administration of the law and also highlight the role that forensic psychiatry has played in educating the Supreme Court and other courts about the clinical realities of mental illness and helping them strike the right balance.

In Panetti v. Quarterman, ${ }^{30}$ the issue was the meaning of the test for competence to be executed and specifically what it means as applied to a prisoner who knew that the state of Texas intended to execute him because he had been convicted of murder, but whose delusional beliefs about why the state was prosecuting him (to stop him from preaching) seemed to erase any genuine understanding of the link between his crimes and the punishment the state intended to impose. In effect, the question was whether the test for competence for execution was "factual" understanding or "rational" understanding. Justice Kennedy's opinion for the Court held that mere formal understanding was not itself sufficient to establish that he was "aware of the purpose of the punishment he was about to suffer." Although Justice Kennedy did not try to define a standard, his opinion demonstrated that a majority of the Court (5-4) recognized that impairments of rationality associated with severe mental illness can erase the person's understanding of the moral meaning of punishment and was willing to tolerate the increased uncertainty associated with a more flexible standard.

By contrast, in Godinez v. Moran, ${ }^{31}$ the Court's seven-to-two majority, in an opinion by Justice Thomas, took the opposite perspective, holding that a capital defendant who had been found competent to stand trial under Dusky did not have to meet a higher standard to be found competent to waive counsel and plead guilty with the intention of seeking a death sentence. This was an appalling result in my opinion. Justice Thomas leaned too heavily in the direction of a simple one-size-fits-all rule and ignored the unjust results that this approach might entail. Fortunately, the balance was corrected somewhat 15 years later in Edwards v. Indiana, ${ }^{32}$ when the Court ruled, in an opinion by Justice Breyer, that the standard for being competent to represent oneself at trial was indeed higher than the Dusky standard. The Court's rulings in both Panetti and Edwards reflect the strong influence of amicus briefs filed jointly by AAPL and the APA.

\section{Integrity}

My third and final observation in praise of your collective efforts over the past 35 years is that you have nurtured and protected the ethical integrity of the psychiatric profession. The challenges are great. The traditional ethics and professional values of medicine are threatened in many ways, including the increasing complexities of our health care system, the ever-expanding accumulation and sharing of personal data about all of us, including health information, and a strong tendency to privilege safety and security over other interests. In a period of such diz- 
zying and profound changes, one could easily become demoralized and resigned to the erosion of traditional values. Yet, in the face of all the odds, American psychiatry has refused to stand down and has been vigilant in its defense of the privacy of the physician-patient relationship and the patient-centered duties of the medical profession.

This observation is supported by the profession's dogged determination to achieve special protection for psychotherapy notes under HIPAA ${ }^{33}$ and to preserve special firewalls in electronic health information systems. It is also supported by the APA's leadership role in banning participation by physicians in interrogations conducted by law enforcement and security agencies ${ }^{34}$ and in condemning the treatment of death-row prisoners for the sole purpose of restoring their competence for execution. ${ }^{35,36}$ Paul Appelbaum recounted these interesting stories earlier, and I need not repeat them.

I am also reminded in this connection of the deliberations of the Task Force on Sexually Dangerous Offenders that Howard chaired. In its 1999 report, ${ }^{37}$ the Task Force minced no words in its opposition to the new generation of Sexually Violent Predator (SVP) laws, which authorize indeterminate confinement of sex offenders just as they are about to complete their terms of punishment, based on the finding that they have a "mental abnormality" that predisposes them to commit sexually violent acts. ${ }^{38}$ The Task Force concluded that even though these laws had been packaged in the form of the traditional model of civil commitment, they were not in fact based on a therapeutic model and they compromised the integrity of the profession by deploying psychiatrists and other mental health professionals as instruments of deception in a scheme designed to achieve purely preventive confinement. The APA's resistance seemed quixotic in the face of the Supreme Court's decision to uphold the Kansas SVP law in Kansas v. Hendricks, ${ }^{39}$ after which such laws proliferated around the country. Fortunately, however, the Supreme Court heeded APA's advice in a subsequent Kansas case and retreated from the most troubling implications of its earlier decision by insisting on a finding of volitional impairment as a predicate for SVP commitment, ruling out commitments based solely on antisocial personality disorder. ${ }^{40}$

I mentioned at the outset of these remarks that the transformation of forensic psychiatry in the $1960 \mathrm{~s}$ and 1970s had it roots in the intertwined develop- ments in medical ethics and human rights arising out of the Nazi medical experiments, when the skills and methods of medicine were appropriated by the state to serve its own ends, in gross violation of human rights, as later codified in the Nuremberg Code. Only a few decades later, psychiatrists were recruited by the Soviet state to suppress and punish dissent in so-called special security psychiatric hospitals. Among the lessons that can be learned from these infamous experiences is that professional independence is an important safeguard for human rights. ${ }^{41,42}$

Physicians must be ready to say no when the state tries to deploy them as agents of its punitive apparatus. Medical skills and knowledge are held in trust for the well-being of patients and the public health. Allowing those skills to be appropriated to the task of interrogation and punishment is incompatible with the supreme aspiration of the profession and would eventually erode the public's trust in the caring role of the doctor. Public trust in the benevolence of physicians is the profession's most important asset, and it is itself a public good that the society itself needs to preserve. $^{36}$

Vigilant protection of the core ethics of the profession is the collective obligation of the profession as a whole, but it is, and has been, a special duty of forensic psychiatry. That duty has been faithfully executed due in no small measure to the habits of ethical reflection that Howard Zonana has modeled and taught for more than three decades.

\section{References}

1. Beecher H: Ethics and clinical research. N Engl J Med 274:135460, 1966

2. U.S. Public Health Service Syphilis Study at Tuskegee: The Tuskeege Timeline. Available at http://www.cdc.gov/nchstp/od/ tuskegee/time.htm. Accessed August 23, 2010

3. Office of Human Subjects Research, National Commission for the Protection of Human Subjects of Biomedical and Behavioral Research: Ethical Principles and Guidelines for the Protection of Human Subjects of Research. The Belmont Report. Bethesda, MD: National Institutes of Health, April 18, 1979. Available at http://ohsr.od. nih.gov/guidelines/belmont.html. Accessed November 2, 2010

4. Trials of War Criminals Before the Nuremberg Military Tribunals Under Control Council Law No. 10. Washington, DC: U.S. Government Printing Office, 1946-1949

5. Katz J: The Nuremberg Code and the Nuremberg Trial: a reappraisal. JAMA 276:1662-6, 1996

6. Baxtrom v. Herold, 383 U.S. 107 (1966)

7. Jackson v. Indiana, 406 U.S. 715 (1972)

8. O'Connor v. Donaldson, 422 U.S. 563 (1975)

9. Addington v. Texas, 441 U.S. 418 (1979)

10. Parham v. J.R., 442 U.S. 584 (1979) 


\section{Howard Zonana and the Transformation of Forensic Psychiatry}

11. Vitek v. Jones, 445 U.S. 480 (1980)

12. Youngberg v. Romeo, 457 U.S. 307 (1982)

13. Jones v. United States, 463 U.S. 354 (1983)

14. Washington v. Harper, 494 U.S. 210 (1990)

15. American Bar Association: Criminal Justice Mental Health Standards. Chicago: Author, 1984

16. Ennis BJ, Litwak T: Psychiatry and the presumption of expertise: flipping coins in the courtroom. Cal L Rev 62:693-752, 1974

17. Morse SJ: Crazy behavior, morals and science: an analysis of mental health law. S Cal L Rev 51:527-654, 1978

18. Appelbaum PS: Almost a Revolution: Mental Health Law and the Limits of Change. New York: Oxford University Press, 1994

19. Frost LE, Bonnie RJ: The Evolution of Mental Health Law. Washington, DC: American Psychological Association, 2001

20. Daubert v. Merrell Dow Pharmaceuticals, Inc., 509 U.S. 579 (1993)

21. Giorgi-Guarnieri D, Janofsky J, Keram E, et al: AAPL practice guideline for forensic psychiatric evaluation of defendants raising the insanity defense. J Am Acad Psychiatry Law 30(suppl):S1-40, 2002

22. Mossman D, Noffsinger SG, Ash P, et al: AAPL practice guideline for the forensic psychiatric evaluation of competence to stand trial. J Am Acad Psychiatry Law 35(suppl):S1-72, 2007

23. Gold LH, Anfang SAS, Drukteinis AM, et al: AAPL practice guideline for the forensic evaluation of psychiatric disability. J Am Acad Psychiatry Law 36(suppl):S1-50, 2008

24. Fed. R. Evid., 704(b)

25. American Bar Association: Criminal Justice Mental Health Standards (ed 3). Limitation on Opinion Testimony Concerning Mental Condition. Standard 7-6.6. Chicago: ABA, 1992

26. Bonnie RJ: Morality, equality and expertise: renegotiating the relationship between psychiatry and criminal law. Bull Am Acad Psychiatry Law 12:5-20, 1984

27. Bonnie RJ, Jeffries JC, Low PW: A Case Study in the Insanity Defense: The Trial of John W. Hinckley, Jr (ed 3). New York: Foundation Press, 2008
28. Stromberg C, Stone A: A model state law on civil commitment of the mentally ill. Harv J Legis 20:275-396, 1983

29. Bonnie RJ, Grisso T: Adjudicative competence and youthful offenders, in Youth on Trial. Edited by Grisso T, Schwartz RG. Chicago: University of Chicago Press, 2000, pp 73-103

30. Panetti v. Quarterman, 551 U.S. 930 (2007)

31. Godinez v. Moran, 509 U.S. 389 (1993)

32. Edwards v. Indiana, 554 U.S. 164 (2008)

33. 45 C.F.R. $\$ 164.501(2000)$

34. Psychiatric Participation in Interrogation of Detainees. APA Position Statement, May 2006. http://www.psych.org/ Departments/EDU/Library/APAOfficialDocumentsandRelated/PositionStatements/200601.aspx. Accessed August 23, 2010

35. Council on Ethical and Judicial Affairs: Physician participation in capital punishment. JAMA 270:365-8, 1993

36. Bonnie RJ: The death penalty: when doctors must say no (editorial). BMJ 305:381-83, 1992

37. Dangerous Sex Offenders: A Task Force Report of the American Psychiatric Association. Washington, DC: American Psychiatric Publishing, Inc., 1999

38. Zonana HV, Bonnie RJ, Hoge SK: In the wake of Hendricks: the treatment and restraint of sexually dangerous offenders viewed from the perspective of American psychiatry, in Protecting Society From Sexually Dangerous Offenders. Edited by Winick BJ, LaFond JQ. Washington, DC: American Psychological Association, 2003, pp 131-45

39. Kansas v. Hendricks, 521 U.S. 346 (1997)

40. Kansas v. Crane, 534 U.S. 407 (2002)

41. Bonnie RJ: Soviet psychiatry and human rights: reflections on the report of the U.S. Delegation. Law Med Health Care 18:123-31, 1990

42. Bonnie RJ, Polubinskaya S: Unraveling Soviet psychiatry. J Contemp Legal Issues 10:279-98, 1999 